\title{
Response to Letter to the Editor Re: Eradicating Jargon-Oblivion-a Proposed Classification System of Medical Jargon
}

J Gen Intern Med 36(4): 1112

DOI: $10.1007 / \mathrm{s} 11606-020-06545-z$

(C) Society of General Internal Medicine 2021 particularly confusing when written. After one of our presentations, one person recalled experiencing anxiety and embarrassment as a teenager when his CT scan report included the phrase, "The patient's testes are unremarkable." It wasn't until medical school that he understood that meant there was nothing abnormal. Similarly, euphemism jargon like "spot on the X-ray" has also been shown to lead to undue anxiety in patients. ${ }^{3}$ Judgmental jargon can also be particularly offputting in the "Open Notes" era, with patients wondering why their doctor insists on saying they "deny alcohol use" when they've in fact been sober for years. ${ }^{4}$

Michael B. Pitt, $M^{1,2}$

Marissa A. Hendrickson, $\mathrm{MD}^{1,2}$

${ }^{1}$ Department of Pediatrics, University of Minnesota School of Medicine,

Minneapolis, MN, USA

${ }^{2}$ University of Minnesota Masonic Children's Hospital, Minneapolis, MN, USA

Corresponding Author: Michael B. Pitt, MD; University of Minnesota Masonic Children's Hospital, Minneapolis, MN, USA (e-mail:mbpitt@umn.edu).

\section{REFERENCES}

1. Lessing JN, Farsad YY, Cumbler E. Letter to the Editor: Eradicating jargon-oblivion - a proposed classification system of medical jargon. JGIM. 2020; In Press.

2. Pitt MB, Hendrickson MA. Eradicating jargon-oblivion-a proposed classification system of medical jargon. J Gen Intern Med. 2020;35(6): 1861-1864.

3. Wiener RS, Gould MK, Woloshin S, Schwartz LM, Clark JA. What do you mean, a spot?: a qualitative analysis of patients' reactions to discussions with their physicians about pulmonary nodules. Chest. 2013;143(3):672-677.

4. Sykes D, Nichols $\mathbf{D}$. There is no denying it, our medical language needs an update. J Grad Med Educ. 2015;7(1):137-138.

Publisher's Note: Springer Nature remains neutral with regard to jurisdictional claims in published maps and institutional affiliations.

Received November 30, 2020

Accepted December 21, 2020

Published online January 27, 2021 